\title{
Mesoscale eddy formation and evolution in the ice-covered ocean
}

\author{
MOTOYOSHI IKEDA \\ Department of Fisheries and Oceans, Physical and Chemical Sciences, \\ Bedford Institute of Oceanography, Dartmouth, Nova Scotia, Canada
}

\begin{abstract}
Generation mechanisms of mesoscale eddies in the ice-covered ocean are studied by using numerical ice-ocean models and discussed with reference to previous papers. The three possible mechanisms of eddy generation, with sea ice as a passive tracer, are current instability, current-eddy interaction and current-bottom topography interaction. The current instability, categorized into barotropic and baroclinic instabilities, may be responsible for eddies near the ice edge associated with a strong current. An eddy can interact with a current, producing additional eddies, where stability of the current is again an important factor for eddy formation. Eddies over bottom topography on the continental shelf are explained by currenttopography interaction; i.e. anticyclones are produced over banks. The particular mechanism that includes ice as an active material is an ice-ocean interaction; i.e. a wind stress is larger over the ice than on open water and induces Ekman pumping and suction, which produce dipole eddy motions in the non-uniformly ice-covered ocean. The eddies are suggested to be important for cross-shelf exchanges of ice and heat as well as determining locations of deep convection.
\end{abstract}

\section{INTRODUCTION}

Various papers have demonstrated mesoscale eddy features in the ice-covered ocean. In the East Greenland Current, Johannessen and others (1983) reported ice-edge meanders, which were accounted for by meanders in the current. They suggested that a barotropic instability was the generation mechanism of the current meanders. Over Molloy Deep, the ice edge has been observed to displace into open water repeatedly by Wadhams and Squire (1983), who suggested a baroclinic instability for generation. Smith and others (1984) showed instead, by a numerical model, that the bottom topography could maintain ocean circulation that advected the ice edge seaward.

In the Labrador Current, two kinds of ice-edge meanders have been observed: shorter meanders with $100 \mathrm{~km}$ wavelengths by LeBlond (1982) and longer meanders with $\sim 200 \mathrm{~km}$ wavelengths by Ikeda (1987). The suggested generation mechanisms, based on simple models, are: (i) a baroclinic instability in the current, responsible for the shorter meanders, and (ii) an interaction between the current and along-shore undulations of the shelf break topography, responsible for the longer meanders. In the Sea of Okhotsk, dipole eddies were observed by Federov and Ginsburg (1989) and could be related to the Oyashio interacting with Kuroshio eddies.

In these papers, eddies have been observed in the marginal ice zone. Ikeda and others (1990), using ice floes over the ice-covered Labrador Shelf, and tracked in NOAA satellite images, showed a mean eddy field. The mean eddy field is related to bottom topography such as banks and saddles on the shelf. Since currents are weak over the shelf, the instability may be less important. It has been suggested that the mean eddy field is generated by interactions between a wide current spreading over the shelf and the bottom topography.

In these observational and modeling studies, three generation mechanisms for mesoscale eddies have been suggested: (i) current instability, (ii) current-eddy interaction and (iii) current-topography interaction. The first two mechanisms are briefly reviewed with references. Evidence of the current-topography interaction over the Labrador Shelf is shown to exist in ice-floe velocity data and is examined by using an eddy-resolving ocean model.

\section{Current instability}

It is well known that eddies are formed from unstable strong ocean currents (e.g. Gulf Stream, Kuroshio) and coastal currents (e.g. California Current, Norwegian Coastal Current). The East Greenland Current and Labrador Current also seem to produce eddies, by which ice is entrained and ejected seaward. There are two kinds of instabilities: a barotropic instability and baroclinic instability.

Johannessen and others (1983) suggested that a barotropic instability was active in the East Greenland Current around $82^{\circ} \mathrm{N}, 10^{\circ} \mathrm{E}$, north of the merging point with the Greenland Shelf, based on the current width 
equivalent to about three internal deformation radii. Wadhams and Squire (1983) suggested a baroclinic instability in the East Greenland Current at $79-80^{\circ} \mathrm{N}$ over the shelf, because the current was estimated to be much wider than the radius. LeBlond (1982) examined the instability of the Labrador Current, referring to a barotropic (one-layer) model and a baroclinic (two-layer) model. Since the baroclinic model provided realistic growth rates and phase speeds, LeBlond suggested baroclinic instability as the generation mechanism of the observed ice-edge meanders.

When instabilities are examined, it should be noted that they are sensitive to the width (Ikeda, 1983). An instantaneous Greenland Current width, from which the instability should be estimated, was observed to be $20 \mathrm{~km}$ in hydrographic data (Bourke and others, 1983) and comparable to the internal deformation radius. Instabilities are also sensitive to bottom topography. In the East Greenland Current and Labrador Current, the isopycnal surface crops out at the sea surface, and the bottom deepens from $200 \mathrm{~m}$ to $3000 \mathrm{~m}$ in a few internal deformation radii. Hence, when trying to isolate the underlying mechanisms of the eddy structures, a primitive equation model with fine vertical and horizontal resolution should be used, such as the model developed by Luther and Bane (1985) for the Gulf Stream.

\section{Current-eddy interaction}

In the Greenland and Labrador seas, eddies can propagate westward by the planetary $\beta$-effects. They also drift westward in the mean basin-scale circulation and merge with the western boundary currents. Thus, the ice edge is expected to be influenced by the eddies that approach the currents from the lefthand side looking downstream. Referring to various modeling papers (e.g. Stern and Flierl, 1987; Ikeda and Lygre, 1989; Smith and Davis, 1989), we may summarize the eddy-current interactions as follows: as an offshore eddy approaches an onshore current, the latter is perturbed to have meanders, which modify the eddy movement. The meander-induced movement is dependent on the sign of the vorticity anomaly associated with the meander in the vicinity of the eddy. Eddy formation is also sensitive to current stability: meanders and eddies are produced continuously downstream of the original eddies, if the current is proved to be unstable.

The East Greenland and the Labrador currents flow over the continental slope. Hence, an interaction between an eddy and the slope should also be considered. Smith (1986) described dispersion of the eddy, suggesting additional eddies (or waves) upstream of the original eddy, which propagates downstream (in the sense of topographically trapped waves). Thus, either a cyclonic eddy or an anticyclonic eddy in the deep ocean can deliver both kinds of eddies to the currents.

In the above work, dynamical processes are accounted for by the ocean, whereas ice is redistributed by ocean circulation as a passive tracer. However, there is another mechanism that operates only in the ice-covered ocean, which includes the ice as an active material. Ekman transport, which is driven by a wind stress and is dependent on ice concentration, induces divergence and convergence, generating eddies. Ice is, in turn, advected by the eddies and redistributed; i.e. this is a wind-driven ice-ocean interaction. Häkkinen (1986) has shown by modeling that a wind stress on the initially meandering ice edge produces eddies in the ocean, while no observed evidence has been provided for this mechanism. In a later section, wind-driven ice-ocean interaction is studied by means of a coupled ice-ocean model. Results are then discussed in terms of the importance of eddies as elements for cross-shelf exchanges of ice and heat, as well as locations of deep convection.

\section{GURRENT-TOPOGRAPHY INTERACTION}

As suggested by Proudman (1916) and Taylor (1917), interaction between an ocean current and bottom topography produces an anticyclonic eddy over a bank (or seamount) and a cyclonic eddy over a trough (or depression). Huppert and Bryan (1976) have shown numerically that a transient process, in which a uniform flow is perturbed by a seamount, produces a pair of anticyclonic and cyclonic eddies on the upstream and downstream sides of the seamount, respectively. As time progresses, the anticyclone tends to locate over the seamount.

Using a two-layer numerical model, Smith and others (1984) have suggested that the Molloy Deep is responsible for a cyclonic eddy, which draws the cold Arctic water, together with its sea ice, seaward off the East Greenland Shelf. However, a two-layer model often overestimates bottom topographic effects. To see this, we examine baroclinic effects in the $2000 \mathrm{~m}$ thick lower layer, which was assumed to be homogeneous in the two-layer model used. The baroclinic effects are estimated by a stratification parameter $S_{\mathrm{t}}=\mathcal{N} H \mid f L_{\mathrm{h}}$ (Huppert and Bryan, 1976), where $\mathcal{N}^{2}=g(-\partial \rho / \partial z) / \rho_{0}$ is the Brunt-Väisälä frequency. Then, baroclinicity becomes important provided $S_{\mathrm{t}} \sim 1$, whereas the flow field is nearly barotropic with $S_{\mathrm{t}} \ll 1$. With the stratification of $0.03 \mathrm{~kg} \mathrm{~m}^{-3} 1000 \mathrm{~m}^{-1}$ below $1000 \mathrm{~m}$ (Johannessen and others, 1987), a water depth $(H)$ of $2000 \mathrm{~m}$ and a horizontal size of the topography $\left(L_{\mathrm{h}}\right)$ of $20 \mathrm{~km}$, one obtains $S_{\mathrm{t}}=0.4$. Thus, baroclinicity should be examined more carefully, and the topographic effects might be weaker than in Smith's model.

The continental shelf is much shallower than the Molloy Deep area. Banks exist on the Labrador Shelf with $\sim 200 \mathrm{~km}$ along-shore intervals. Thus, topographic effects are expected to be more clearly seen over the Labrador Shelf, as examined in Ikeda and others (1990). A data set of NOAA images was used to show mean eddy field. Ice floes were tracked between two consecutive images, and the direct wind-driven component was removed based on the statistical results that the component is $1.7 \%$ of a geostrophic wind speed with a zero turning angle. The ice velocity vectors, collected in about 20 maps from 1984-86, are averaged and shown in Figure 1. Since most data were collected more than $20 \mathrm{~km}$ from the coast, internal ice stresses may be negligible.

An objective analysis method was developed to construct a stream function map from randomly distributed velocity data. The assumption of non-divergence can be justified on the basis that the velocity field is likely to reflect ocean flow, which, to the lowest order, is non- 


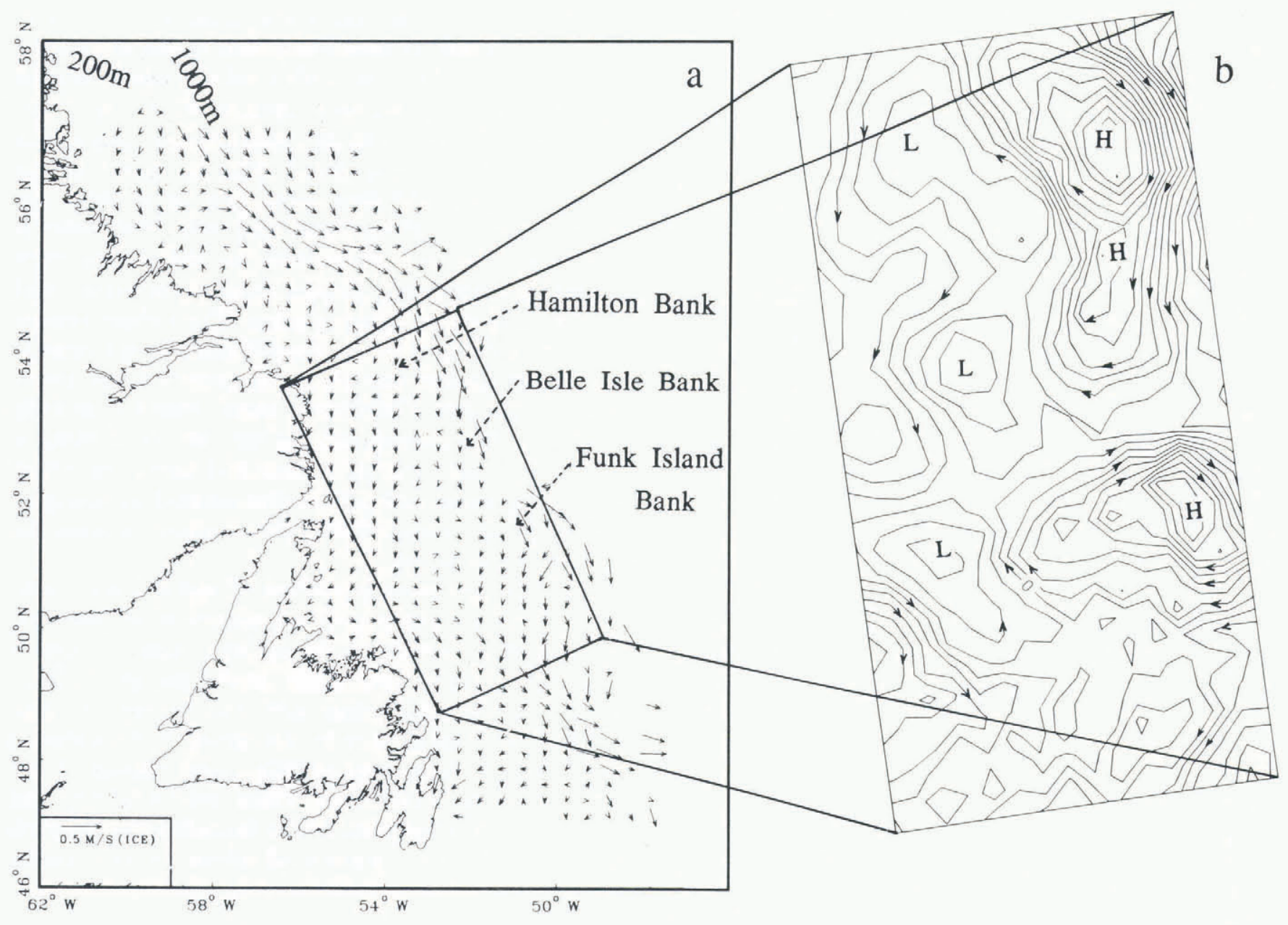

Fig. 1. The mean (a) ice velocity vectors over the Labrador and the Newfoundland shelves after the direct winddriven components removed and (b) stream function, objectively drawn from (a) in the rectangular box. $L$ and $H$ indicate cyclonic and anticyclonic gyres.

divergent. The stream function shown in Figure 1 has distinct features: three anticyclones over the Hamilton, Belle Isle and Funk Island banks. The clockwise circulation around the southwestern corner is reminiscent of the coastal current near Newfoundland. A weaker coastal current is also present in the northern part of the analysis domain.

A quasi-geostrophic, eddy-resolving model has been developed to study the mechanisms that generate mesoscale features (e.g. Ikeda and others, 1989). The three-layer version is used in this paper and shown in Figure 2 for demonstrating that the observed mean eddy field can be accounted for by current-topography interactions. The model is a rectangle with a $400 \mathrm{~km}$ along-shore length and a $300 \mathrm{~km}$ cross-shore length, having three layers with thicknesses of $150 \mathrm{~m}, 200 \mathrm{~m}$ and $650 \mathrm{~m}$ from top to bottom. Differences in density are $0.8 \mathrm{~kg} \mathrm{~m}^{-3}$ between the top and the second layers, and $0.2 \mathrm{~kg} \mathrm{~m}^{-3}$ between the second and the bottom layers. The offshore portion has a depth of $1000 \mathrm{~m}$ with a three-layer stratification; the shelf region is $350 \mathrm{~m}$ deep, consists of two layers and has a width of $200 \mathrm{~km}$.

This topography is obviously an idealized representation of the real topography of the Newfoundland Shelf. It will be made more realistic by incorporating two seamounts and one depression on the shelf region with depth deviations of $55 \mathrm{~m}$. The shapes have Gaussian structure with an $e$-folding scale of $50 \mathrm{~km}$. The centres of the seamounts are located $150 \mathrm{~km}$ off the coast, whereas that of the depression is $50 \mathrm{~km}$ off the coast. The distance between the seamounts is $200 \mathrm{~km}$ and consistent with the distances between two banks in a chain of the Hamilton, Belle Isle and Funk Island banks.

The basic equations express the conservation of potential vorticity in an inviscid flow overlying gentle bathymetry on an $f$-plane. The initial currents consist of three components: the first one is a uniform current over the shelf $(0<y<200 \mathrm{~km})$, having zero velocity in the deep portion $(y>200 \mathrm{~km})$. The other two components are the inshore and offshore branches of the Labrador Current. The two branches have Gaussian cross-shore structure with a half $e$-folding scale of $20 \mathrm{~km}$. The axes of the inshore and offshore branches are at $50 \mathrm{~km}$ and $225 \mathrm{~km}$ off the coast, respectively. The velocities are $0.09 \mathrm{~m} \mathrm{~s}^{-1}$ for the uniform shelf current in the two upper layers. The inshore branch has currents of $0.3 \mathrm{~m} \mathrm{~s}^{-1}$ in the top layer and zero in the second layer. The offshore branch has a current of $0.3 \mathrm{~m} \mathrm{~s}^{-1}$ in the two upper layers and $0.15 \mathrm{~m} \mathrm{~s}^{-1}$ in the third layer.

The initial uniform flow is perturbed by interactions with the bottom topography; i.e. compression and stretching of the water column over the seamounts 

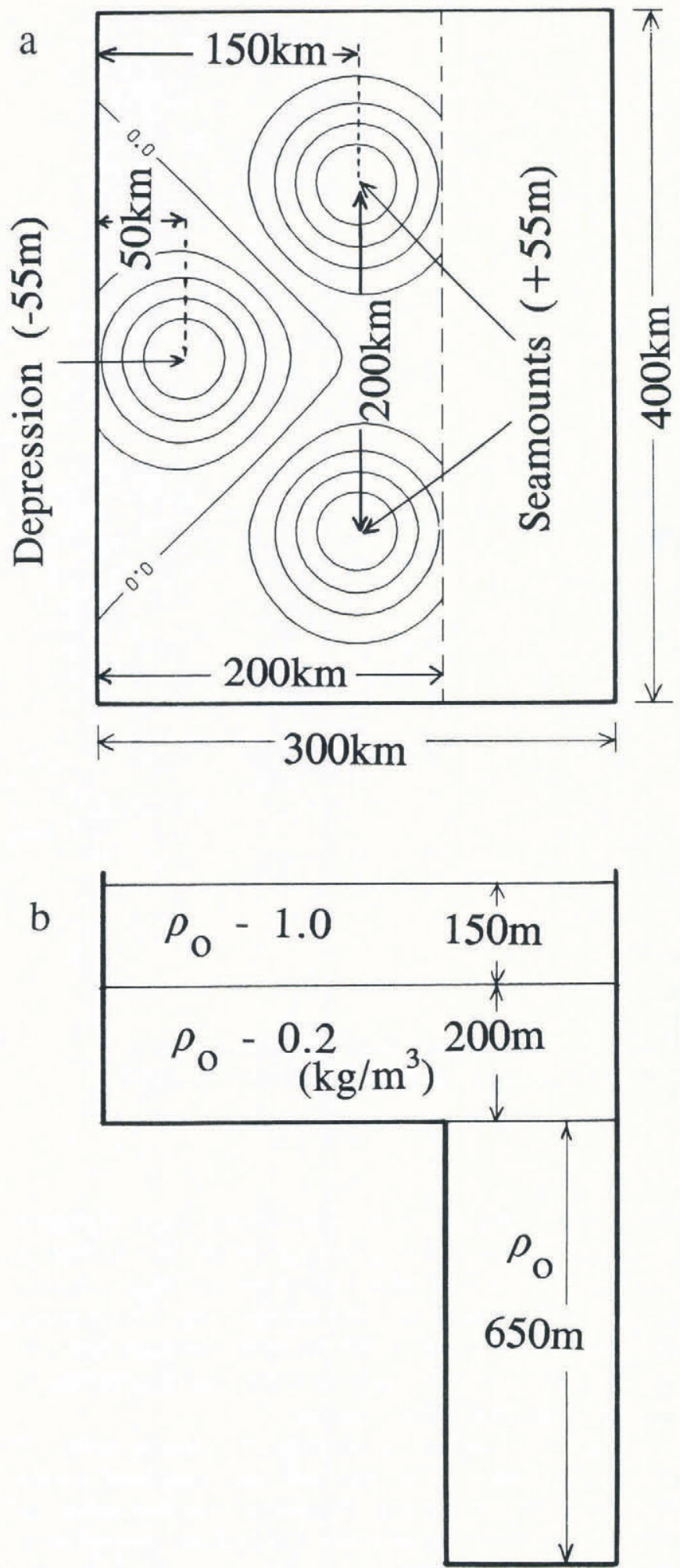

Fig. 2. (a) Plan view of the numerical model with bottom topography, including two seamounts and depression, and (b) the cross-section.

produces anticyclonic and cyclonic rotations in the upstream and downstream sides, respectively. Over the depression, the perturbations have opposite rotations. The rotations are advected by the along-shore flow, and after $t=16 \mathrm{~d}$, steady anticyclones and cyclones are situated over the seamounts and depression, respectively (Fig. 3). The inshore branch flows around the cyclone and the downstream anticyclone.
Potential vorticity, which is a conserved quantity in this model, is used to track water. It is shown in Figure 3 that some part of the water that initially exists over the upstream seamount has been captured there. The larger part of the water that initially exists over the downstream seamount is advected away. Hence, more intense compression and stretching occur, and the rotations are stronger over the downstream seamount. The water is advected from the depression to the downstream seamount, experiencing thereby intense compression and thus generating the strong rotation. The inshore branch seems to contribute to the intensification of the cyclone over the depression and the anticyclone over the downstream seamount. The inshore water, which is initially limited to the onshore side of the inshore branch, is stretched seaward by the cyclone and almost entrained into the upstream anticyclone. The seaward stretching of the inshore water has large features consistent between the top and second layers.

The inshore water is pinched off and is floating into the downstream anticyclone; the inshore water has been pinched off as an eddy in the top layer, and the other is about to separate. Both eddies overlie the second-layer water that initially exists over the depression. The pinched-off inshore water in the second layer underlies the top-layer water that initially exists offshore of the inshore branch. Thus, these eddies are baroclinic, and baroclinicity is important. Minor meanders are observed associated with the pinched-off eddies in the stream functions.

\section{ICE-OGEAN INTERAGTION}

Another mechanism for generating mesoscale features is an interaction between ice and ocean. Wind stress on the ice is larger than that on open water, producing Ekman divergence (or convergence) in the vicinity of the ice edge. The wind experiences ice with spatial variabilities in concentration and surface roughness; this can create divergence/convergence and will result in cyclonic/anticyclonic circulation in the ocean. This eddy-like structure will accordingly advect the ice and thus modify the ice distribution. In turn, the ocean circulation is correspondingly modified by the updated ice cover.

Only mechanisms relevant to the focused physics in this section are retained in the ice model. Ice is assumed to be free-drifting; no internal ice stress is considered. Ice concentration has a maximum initial value of 0.8 to justify this assumption. Thermodynamics are excluded, and so no formation or melting of ice occurs. This simplification is likely to be a valid first approximation in the pack-ice region, provided the time scale is restricted to a few days. Here, the ice anomaly in the pack-ice region is considered to be purely mechanical, even though thermodynamics may be important in the marginal ice zone. The ice thickness is assumed to be constant, and ice distribution is represented by concentration only.

The ice motion is assumed to be driven by four external forcing mechanisms: wind stress, ice-water stress, Coriolis force and the pressure gradient due to the tilt of the sea surface. Non-linear advective terms are omitted, and this is justified in view of sub-inertial time scales. The 
$\mathrm{P}_{1}$

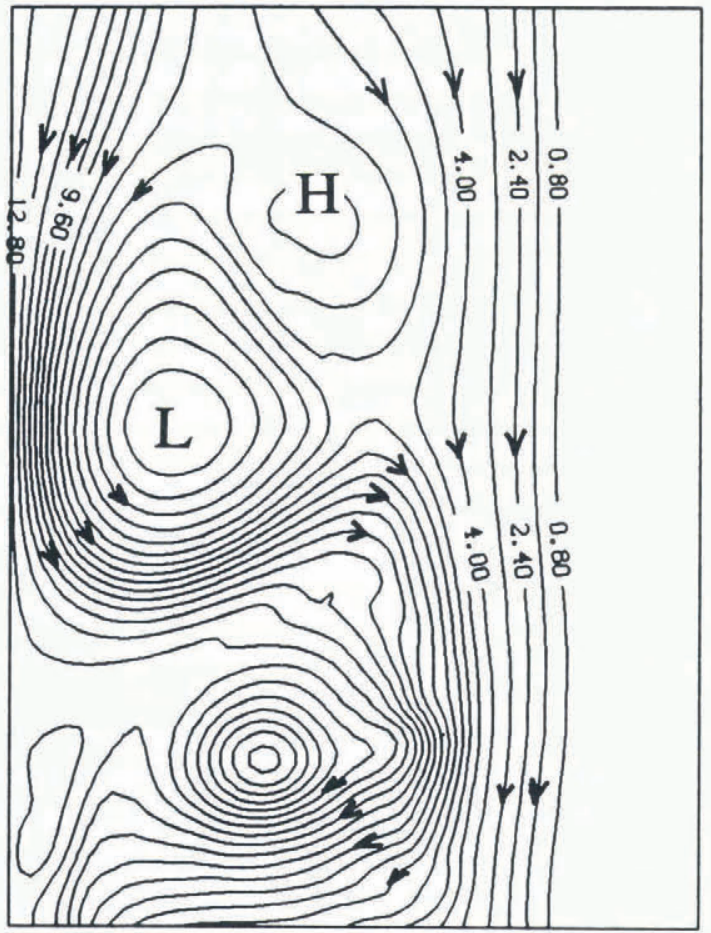

$\mathrm{P}_{2}$

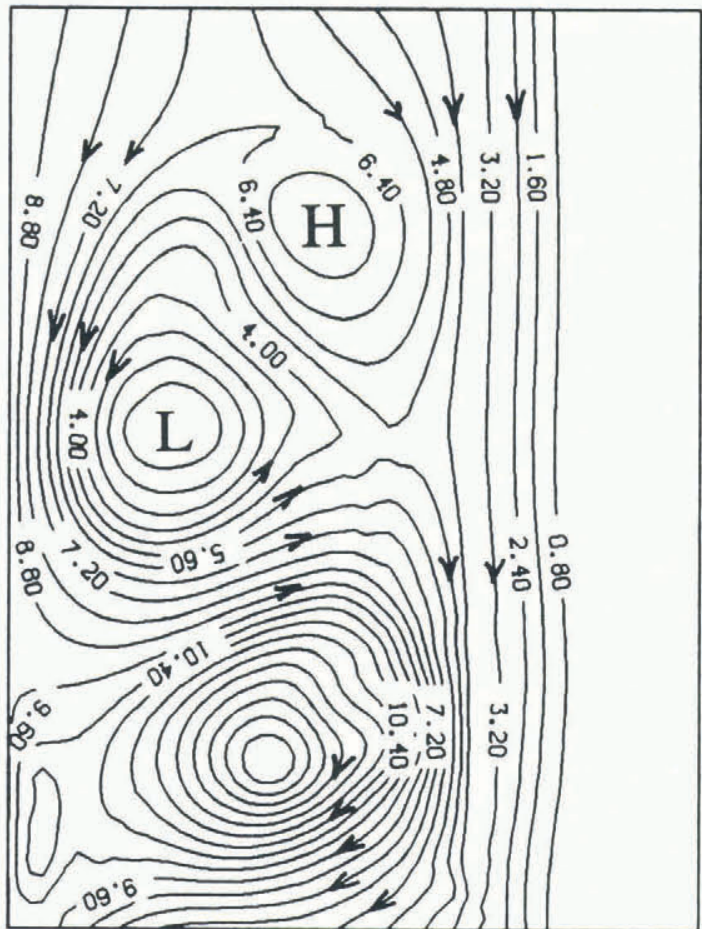
2

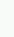
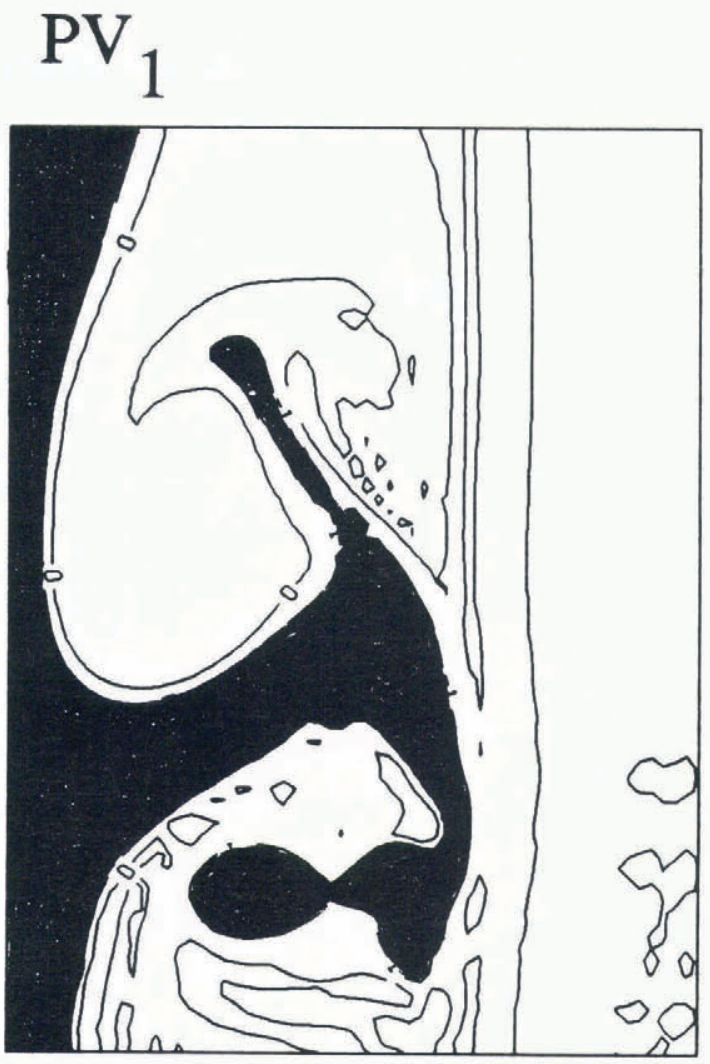

Ikeda: Eddy formation and evolution in ice-covered ocean 
momentum balance is quasi-steady, the time derivative terms being omitted, because a wind stress balances an ice-water stress in $\sim 1000 \mathrm{~s}$, which is much shorter than the time scale concerned within this paper.

The wind stress on the ice is assumed to be larger than that on water by a factor of two. The ice-water stress is given by a quadratic stress law. The water velocity at the surface is defined to be a sum of the geostrophic current in the upper layer and the Ekman velocity (averaged in the Ekman layer). The Ekman velocity is determined from the stress on the sea surface and ice-ocean interface. The ice momentum equations determine the ice velocity relative to the surface-water velocity.

The quasi-geostrophic ( $\mathrm{QG})$, eddy-resolving model, developed in Ikeda and others (1989), is used to study the mechanisms for generating the mesoscale features. In the previous papers, no surface stress was applied, but in this section wind stress and ice-water stress are incorporated instead. The two-layer version of the model is used. The upper and lower layers have typical thicknesses of $50 \mathrm{~m}$ and $250 \mathrm{~m}$, respectively. Density difference is chosen to be $1 \mathrm{~kg} \mathrm{~m}^{-3}$, and the $f$-plane approximation with a constant Coriolis parameter is invoked.

In deriving the governing equations for the conservation of the potential vorticity, as done by McCartney (1975), all terms are expanded in Taylor series of the (internal) Rossby number. The lowest order terms

describe the geostrophic balance and, then, the $Q G$ potential vorticity equations are derived from the second order terms. They bring about the terms particular for the surface stress as vorticity input due to Ekman divergence. However, the Ekman velocity is excluded in the advection terms of the ocean momentum equations because it is of higher order.

The calculation domain is chosen to be a $114 \mathrm{~km}$ by $114 \mathrm{~km}$ square. One of its sides is parallel to the $x$-axis and orientated in the direction of the wind. A solution is assumed to be periodic in the $x$-direction. The $y$ boundaries are impermeable and slippery for the geostrophic ocean current, whereas they are open for the ice and the Ekman flow.

An initially circular ice patch (an isolated positive ice anomaly) is examined. Its initial ice concentration is Gaussian, with a maximum value of 0.8 and and $e$-folding scale of two internal deformation radii $(11.4 \mathrm{~km})$ (decaying to zero at the far field). Although this ice distribution is rather special, the processes that are associated with the anomaly can be generalized for non-zero concentration at the far field, because a difference in Ekman transport is essential for oceanic processes. The wind stress of $0.1 \mathrm{~Pa}$, acting in the positive $x$ direction, is held constant for $3.3 \mathrm{~d}$, after which the wind ceases. The calculation is carried out for $6.6 \mathrm{~d}$ after wind cessation.

The ice concentration and stream functions are shown
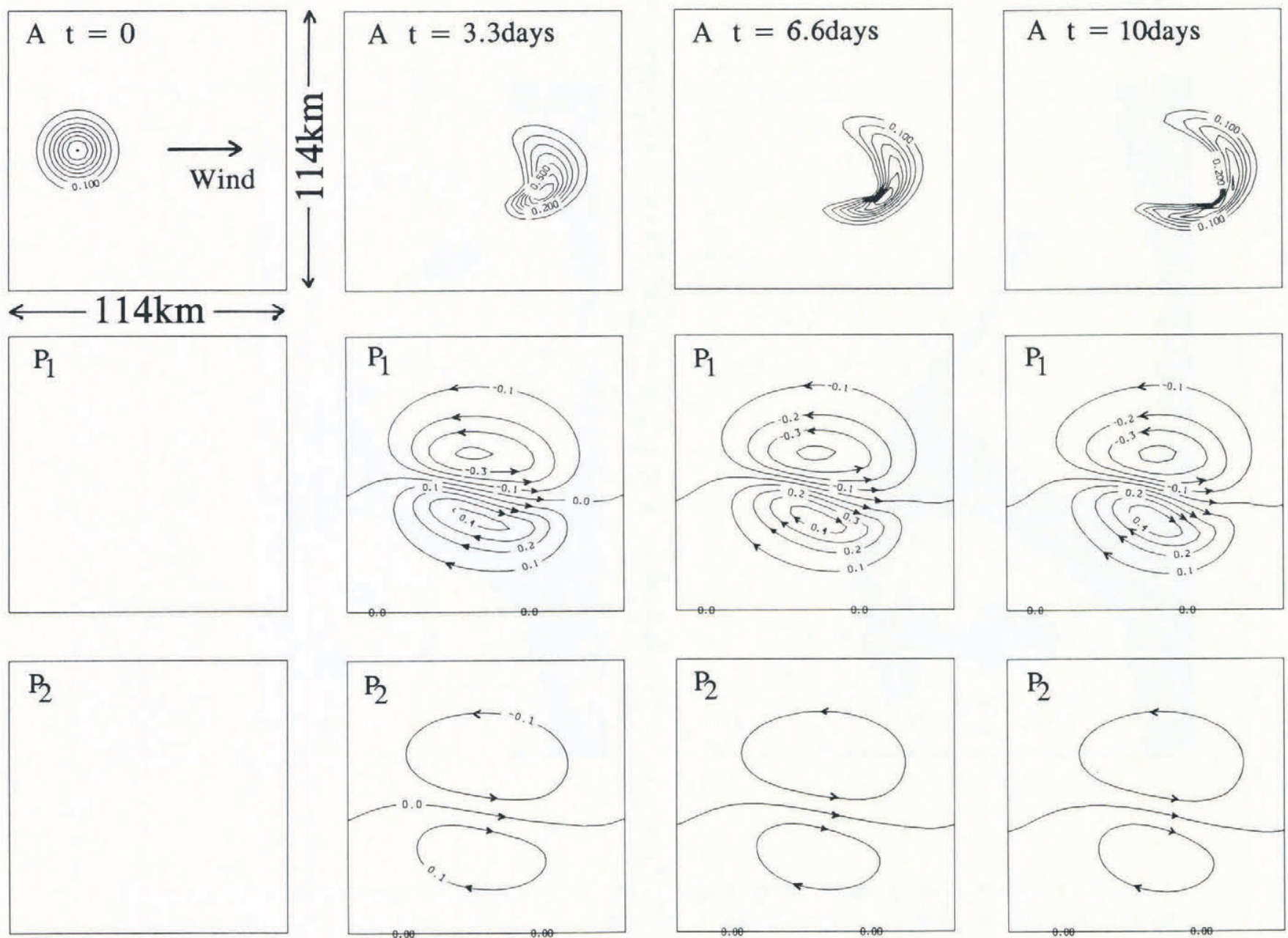

Fig. 4. The ice concentration $A$ (top panels), upper-layer stream function $p_{1}$ (middle panels) and lower-layer stream function $p_{2}$ (bottom panels) for $t=0,3.3,6.6$ and 10.0 d, starting with a positive ice anomaly. The contour intervals are 0.1 for $A$ and $1.14 \times 10^{2} \mathrm{~m}^{2} \mathrm{~s}^{-1}$ for $p_{1}$ and $p_{2}$. 


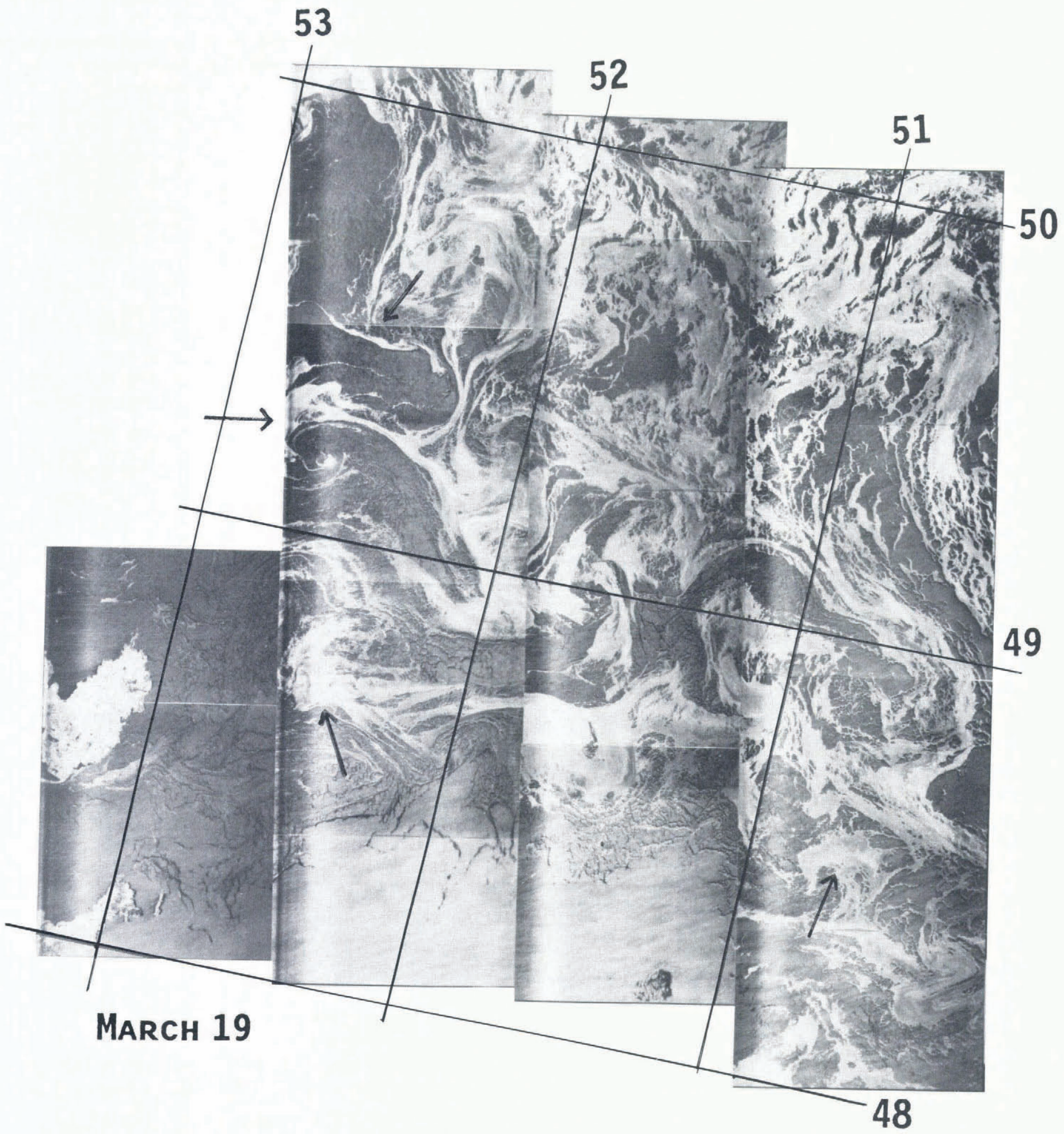

Fig. 5. A SAR image collected on 19 March 1990 by the Canada Centre for Remote Sensing airborne system. The bright portion near the left boundary is part of Newfoundland, and sea ice with bright colour is present in almost the entire domain. Mesoscale dipole eddy features are indicated by arrows.

in Figure 4. The ice patch is advected by the wind at a speed of $\sim 0.2 \mathrm{~m} \mathrm{~s}^{-1}$ mostly to positive $x$ and slightly to negative $y$; turning to the right from the wind direction. Dipole eddy structures are developing during the wind forcing, with an anticyclonic eddy and a cyclonic eddy on the right and left of the ice patch, respectively, when looking down in the downwind direction. The eddies are more intense in the upper layer than in the lower layer. The maximum current speed betweent the two eddies is $\sim 0.06 \mathrm{~m} \mathrm{~s}^{-1}$. They travel to positive $x$ at a speed of $\sim 0.02 \mathrm{~m} \mathrm{~s}^{-1}$ both during the wind forcing and after its cessation. Advection is provided by rotational effects of each eddy on the other. The ice patch is deformed by the dipole eddies and becomes arch-shaped in $10 \mathrm{~d}$.

The processes occurring under the ice anomalies are described as follows: the Ekman transport is larger beneath the high anomaly than the surrounding area, and it induces convergence and divergence on the right and left, respectively, when looking in the downwind direction. These convergent and divergent flow patterns 
generate the dipole eddies, which advect themselves downwind and form the arch shape of the ice anomaly. The processes with a low concentration anomaly are predicted as follows: a wind stress on the anomaly induces opposite divergence and convergence. As a result, upwindtravelling dipole eddies would be generated.

The realistic values of the parameters yield an ocean current velocity of $0.05-0.1 \mathrm{~m} \mathrm{~s}^{-1}$. Thus, circulation, induced by a wind stress on an ice anomaly, could be significant in ocean flow fields. In particular, it is responsible for the deformation of ice anomalies. Dipoleeddy features, hammer head and arch shapes of ice distribution observed over the Labrador and Newfoundland shelves (Fig. 5) and in the Sea of Okhotsk, could be accounted for by mesoscale ocean flow field induced by the ice anomalies themselves.

\section{DISCUSSION}

Anticyclones produced over banks replace the shelf water by the offshore water and eject sea ice into the Labrador Current. The roles of the cross-shore exchange are estimated from the stream function (Fig. 1). The mean cross-shore flow (area transport) between the Belle Isle and Funk Island banks is $\sim 5 \times 10^{3} \mathrm{~m}^{2} \mathrm{~s}^{-1}$. This tranport is minor compared with the southward ice transport, which is estimated from historical data to be a product of the along-shore velocity $\left(=0.1-0.2 \mathrm{~m} \mathrm{~s}^{-1}\right)$ and the shelf width $(=200 \mathrm{~km})$, resulting in an areal transport of 2 to $4 \times 10^{4} \mathrm{~m}^{2} \mathrm{~s}^{-1}$.

However, the cross-shore heat transport should be estimated separately. It can be significant, because the cross-shore temperature gradient is much larger than its along-shore counterpart. The heat transport is estimated as follows: the temperature difference is estimated to be $5^{\circ} \mathrm{C}$ between the shelf and offshore and is assumed to be limited in the top $100 \mathrm{~m}$. If this heat is uniformly distributed over the $600 \mathrm{~km}$-long and $20 \mathrm{~km}$-wide shelf, it is equivalent to $80 \mathrm{~W} \mathrm{~m}^{-2}$. This value is significant as compared to a typical air-sea heat flux of $\sim 200 \mathrm{~W} \mathrm{~m}^{-2}$ through open water over the shelf in winter, or comparable with heat flux through ice. Heat of fusion associated with seaward transport of ice, which melts offshore, is minor: for $1 \mathrm{~m}$-thick ice that melts it would be equivalent to $\sim 15 \mathrm{~W} \mathrm{~m}^{-2}$.

Deep water is formed in the Greenland and Weddell seas and is an important component in the global water distribution. Deep water formation takes place when the near-surface layer becomes denser than the lower layer water owing to cooling and evaporation; i.e. static instability. Thus, overturning must be sensitive to the fresh water input to the surface layer. As a major possible source of fresh water, sea-ice distribution is one of the key parameters to determine location for deep convection. The larger the cross-shore ice transport is, the less will correspondingly be the deep convection in the areas. This aspect should be studied further.

\section{ACKNOWLEDGEMENTS}

The author acknowledges collaboration with various scientists; the objective analysis method was developed by P. Haugan, ice-floe velocity maps were contructed by I. Perterson, and the airborne SAR image was collected by C. Livingstone. The work in this paper was supported by the Federal Panel on Energy Research and Development. The author thanks S. Prinsenberg and C. Tang for BIO in-house reviews.

\section{REFERENCES}

Bourke, R.H., J.L. Newton, R.G. Paquette, and M.D. Tunnicliffe. 1987. Circulation and water masses of the East Greenland shelf. 7. Geophys. Res., 92(C7), 67296740.

Fedorov, K.N. and A.I. Ginsburg. 1989. Mushroom-like currents (vortex dipoles): one of the the most widespread forms of non-stationary coherent motion in the ocean. In Nihoul, J. C. J. and B. M. Jamart, eds. Mesoscale/synoptic coherent structures in geophysical turbulence. Amsterdam, Elsevier, 1-14.

Häkkinen, S. 1986. Coupled ice-ocean dynamics in the marginal ice zones: upwelling/downwelling and eddy generation. F. Geophys. Res., 91(C1), 819-832.

Huppert, H.E. and K. Bryan. 1976. Topographically generated eddies. Deep-Sea Res., 23(8), 655-679.

Ikeda, M. 1983. Linear instability of a current flowing along a bottom slope using three-layer model. 7 . Phys. Oceanogr., 13, 208-223.

Ikeda, M. 1987. Modeling interpretation of mesoscale meanders of the ice edge off the Labrador coast observed in NOAA satellite imagery. F. Phys. Oceanogr., 17(9), 1468-1483.

Ikeda, M. and K. Lygre. 1989. Eddy-current interactions using a two-layer quasi-geostrophic model. In Nihoul, J. C. J. and B. M. Jamart, eds. Mesoscale/synoptic coherent structures in geophysical turbulence. Amsterdam, Elsevier, 277-291.

Ikeda, M., J.A. Johannessen, K. Lygre, and S. Sandven. 1989. A process study of mesoscale meanders and eddies in the Norwegian coastal current. 7. Phys. Oceanogr., 19, 20-35.

Ikeda, M., P.M. Haugan, and I. Peterson. In press. Topography-driven mesoscale eddies detected by ice floe movement. F. Geophys. Res.

Johannessen, J.A., and 11 others. 1987. Mesoscale eddies in the Fram Strait marginal ice zone during the 1983 and 1984 Marginal Ice Zone Experiment. 7. Geophys. Res., 92(7), 6754-6772.

Johannessen, O.M., J.A. Johannessen, J. Morison, B.A. Farrelly, and E.A.S. Svendsen. 1983. Oceanographic conditions in the marginal ice zone north of Svalbard in early fall 1979 with an emphasis on mesoscale processes. 7. Geophys. Res., 88(C5), 2755-2769.

LeBlond, P.H. 1982. Satellite observations of Labrador current undulations. Atmosphere-Ocean, 20, 129-142.

Luther, M.E. and J.M. Bane, $\mathcal{F r}$. 1985. Mixed instabilities in the Gulf Stream over the continental slope. F. Phys. Oceanogr., 15, 3-23.

McCartney, M.S. 1975. Inertial Taylor columns on a beta plane. F. Fluid Mech., 68, 71-95.

Proudman, J. 1916. On the motion of solids in a liquid possessing vorticity. Proc. R. Soc. London, Ser. A, 92, 408424. 
Smith, D.C., IV. 1986. A numerical study of Loop Current interaction with topography in the western Gulf of Mexico. 7. Phys. Oceanogr., 16, 1260-1272.

Smith, D.C., IV, and G.P. Davis. 1989. A numerical study of eddy interaction with an ocean jet. J. Phys. Oceanogr., 19, 975-986.

Smith, D.C., IV, J.H. Morison, J.A. Johannessen, and N. Untersteiner. 1984. Topographic generation of an eddy at the edge of the East Greenland Current. F. Geophys. Res., 89(C5), 8205-8208.
Stern, M.E. and G.R. Flierl. 1987. On the interaction of a vortex with a shear flow. F. Geophys. Res., 92(C10), 10,733-10,744.

Taylor, G.I. 1917. Motion of solids in fluids when the flow is not irrotational. Proc. R. Soc. London, Ser. A, 93, 99-113.

Wadhams, P. and V.A. Squire. 1983. An ice-water vortex at the edge of the East Greenland Current. 7. Geophys. Res., 88(C5), 2770-2780.

The accuracy of references in the text and in this list is the responsibility of the author, to whom queries should be addressed. 